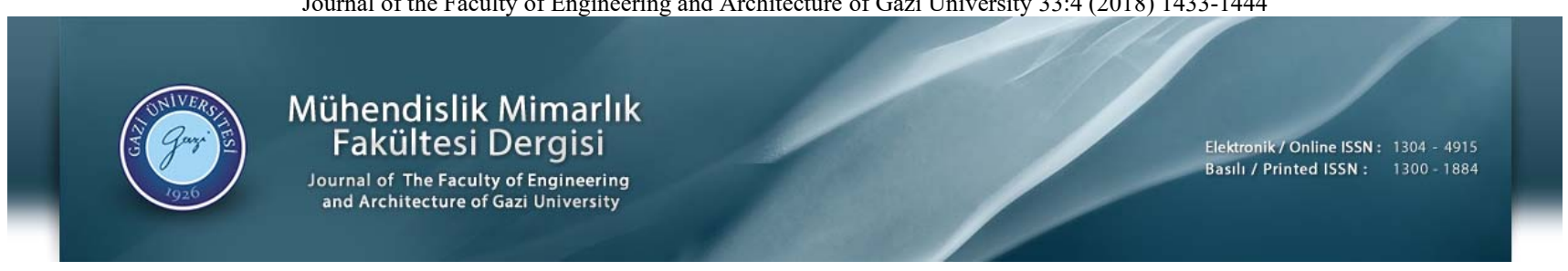

\title{
Pitch based carbon fiber production
}

\author{
Gamzenur Özsin' ${ }^{1}$, Ayșe Eren Pütün ${ }^{2}$ \\ ${ }^{1}$ Bilecik Sheikh Edebali University, Faculty of Engineering, Department of Chemical Engineering, Istanbul, 11230, Turkey \\ ${ }^{2}$ Anadolu University, Faculty of Engineering, Chemical Engineering Department, Eskisehir, 26555, Turkey
}

\section{Highlights:}

- Characteristics of carbon fiber

- Pitch synthesis

- Pitch-based carbon fiber production process

Keywords:

- Carbon fiber

- Pitch

- Stabilization

- Carbonization

- Graphitization

\section{Article Info:}

Review Article

Received: 27.03.2017

Accepted: 26.07.2017

DOI:

10.17341/gazimmfd.4164440

\section{Acknowledgement:}

The Scientific and

Technological Research

Council of Turkey

(TÜBİTAK), Kyushu

University Institute for

Materials Chemistry and

Engineering- Laboratory of

Carbon Materials Science

\section{Correspondence:}

Author:Gamzenur Özsin e-mail:

gozsin@anadolu.edu.tr phone: +902282141534

\section{Graphical/Tabular Abstract}

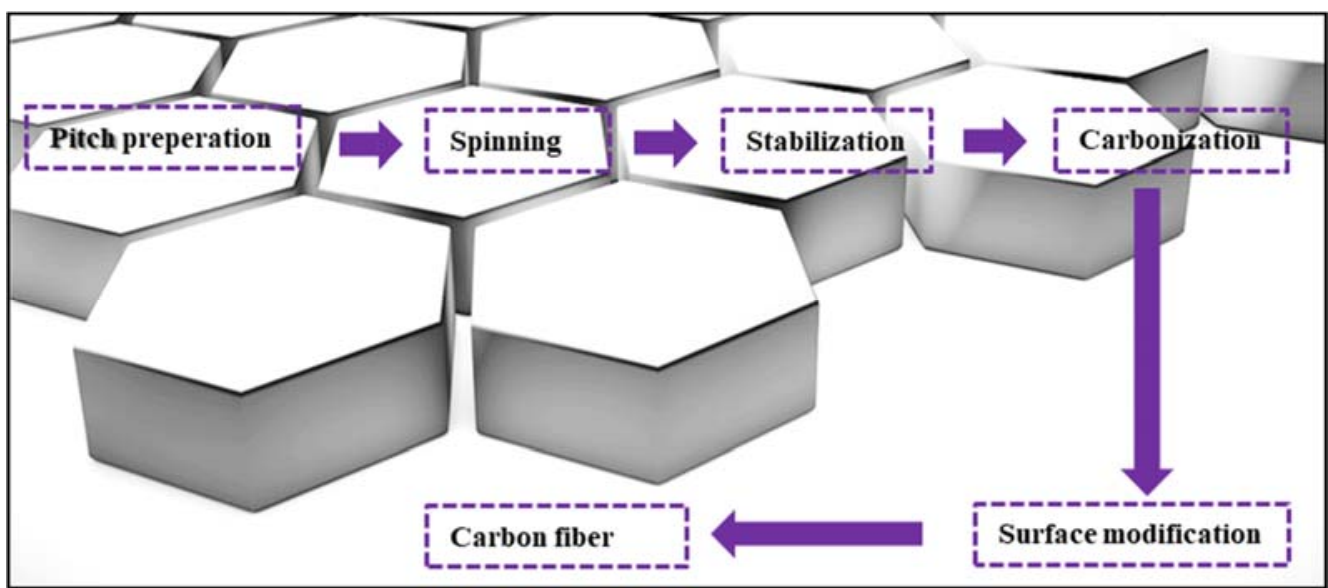

Figure A. Pitch-based carbon fiber production proess

Purpose: Carbon fiber, which has unique physical, chemical and biological properties, is a versatile material in fiber form composed of carbon atoms arranged in hexagonal structure. In the industrial production of carbon fibers, whose potential application areas develop by day, PAN (polyacrylonitrile) is generally used. However, the existing production technologies of PAN-based carbon fiber production have became unable to reduce production costs. By pitch-based carbon fiber production, which has a smaller market share than PAN, it is possible to produce carbon fiber with a cheaper way and a higher efficiency than PAN. Today, many studies have been carried out on the production of carbon fibers from isotropic and mesophase pitches that can be synthesized from different sources, development of production processes and end product characteristics. In this study, a literature review on pitch-based carbon fiber production was carried out and production processes were investigated.

Theory and Methods: Processes for the pitch-based carbon fiber production are reviewed.

Results: Extensive results of the current literature about pitch-based carbon fiber production are given.

\section{Conclusion:}

By considering technological and ecological balance together with economy, the development of pitch-based carbon fiber production together with PAN-based carbon fiber is of great importance for the carbon fiber market. Therefore, the production process was reviewed by explaining structure-property relationship and process variables. 


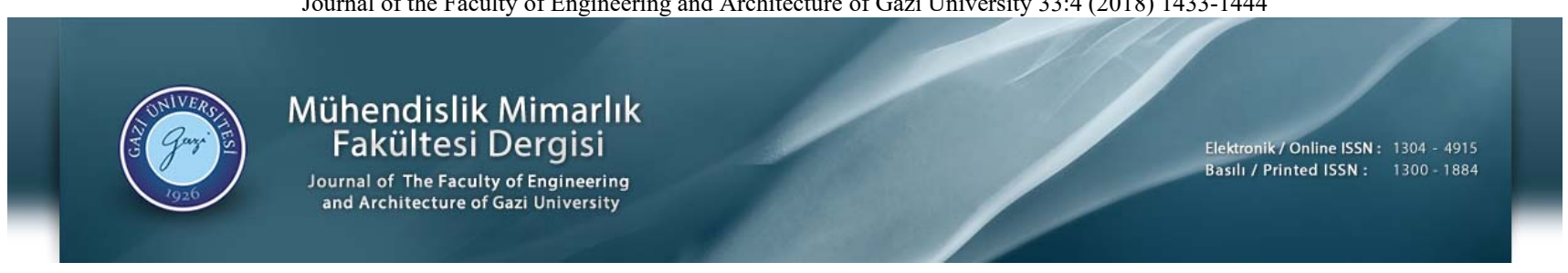

\title{
Zift esaslı karbon fiber üretimi
}

\author{
Gamzenur Özsin ${ }^{1 *(\mathbb{D})}$, Ayşe Eren Pütün ${ }^{2}$ (D) \\ ${ }^{1}$ Bilecik Şeyh Edebali Üniversitesi, Mühendislik Fakültesi, Kimya Mühendisliği Bölümü, Bilecik, 11230, Türkiye \\ ${ }^{2}$ Anadolu Üniversitesi, Mühendislik Fakültesi, Kimya Mühendisliği Bölümü, Eskişehir, 26555, Türkiye
}

\section{Ö N E Ç I K A N L A R}

- Karbon fiber özellikleri

- Zift sentezi ve zift özelliklerinin karbon fiber özelliklerine etkisi

- Zift esaslı karbon fiber üretim süreci

Makale Bilgileri

Tarama Makalesi

Geliş: 27.03.2017

Kabul: 26.07.2017

DOI:

$\overline{10.17341 / \text { gazimmfd. } 4164440}$

Anahtar Kelimeler:

Karbon fiber,

zift,

stabilizasyon,

karbonizasyon,

grafitizasyon

\section{ÖZET}

Benzersiz fiziksel, kimyasal ve biyolojik özelliklere sahip olan karbon fiber (karbon elyaf), hekzagonal yapıda dizilmiş karbon atomlarından oluşan lif şeklinde çok yönlü bir malzemedir. Günden güne potansiyel uygulama alanları gelişmekte olan karbon fiberlerin endüstriyel üretiminde genel olarak PAN (poliakrilonitril) kullanılmaktadır. Ancak, PAN esaslı karbon fiber üretiminin mevcut olan üretim teknolojileri, ürün maliyetinin azaltılmasını sağlayamamaktadır. Pazar payı PAN'a oranla daha az olan zift esaslı karbon fiber üretimi ile PAN esaslı karbon fiberlere göre daha ucuz ve daha yüksek verimlerle karbon fiber üretimi mümkündür. Günümüzde, farklı kaynZift aklardan sentezlenebilecek izotropik ve mezofaz ziftlerden karbon fiber eldesi, üretim süreçlerinin ve son ürün özelliklerinin geliştirilmesi üzerine birçok çalışma yürütülmektedir. Bu çalışmada, zift esaslı karbon fiber üretimi hakkında bir literatür taraması yapılarak, üretim süreçleri incelenmiştir.

\section{Pitch based carbon fiber production}

\section{H I G H L I G H T S}

- Characteristics of carbon fiber

- Pitch synthesis and effect of pitch properties on carbon fiber characteristics

- $\quad$ Pitch-based carbon fiber production process

Article Info

Review Article

Received: 27.03.2017

Accepted: 26.07.2017

DOI:

10.17341/gazimmfd.4164440

Keywords:

Carbon fiber,

pitch,

stabilization,

carbonization,

graphitization

\section{ABSTRACT}

Carbon fiber, which has unique physical, chemical and biological properties, is a versatile material in fiber form composed of carbon atoms arranged in hexagonal structure. In the industrial production of carbon fibers, whose potential application areas develop by day, PAN (polyacrylonitrile) is generally used. However, the existing production technologies of PAN-based carbon fiber production have became unable to reduce production costs. By pitch-based carbon fiber production, which has a smaller market share than PAN, it is possible to produce carbon fiber with a cheaper way and a higher efficiency than PAN. Today, many studies have been carried out on the production of carbon fibers from isotropic and mesophase pitches that can be synthesized from different sources, development of production processes and end product characteristics. In this study, a literature review on pitch-based carbon fiber production was carried out and production processes were investigated.

\footnotetext{
*Sorumlu Yazar/Corresponding Author: gozsin@anadolu.edu.tr; gamzenur.ozsin@bilecik.edu.tr / Tel: +90 2282141534 


\section{GİRIŞ (INTRODUCTION)}

Karbon fiber (karbon elyaf), en az \%92 oranında elementel karbon içeren, üstün mekanik, kimyasal, termal ve biyolojik özellikleri olan lif şeklinde bir malzemedir. Şekil 1'de görülebileceği gibi karbon fiberlerin yapısında fiber eksenine paralel iki boyutlu karbon şeritler bulunmaktadır. Bu karbon şeritlerin bazıları fiber ekseni boyunca uzanırken, bazıları da düzensiz bir şekilde yönlenirler. Fiber ekseni boyunca uzanan şerit halindeki tabakalar karmaşık bir biçimde birbirlerine bağlıdır. Karbon fiberlerin mikro yapısındaki kıvrımlar ve şeritler arasındaki güçlü molekül içi bağlardan dolayı, karbon fiberler birçok malzemeden üstün mekanik özelliklere sahiptirler [1].

Karbon fiberlerin en büyük avantajı düşük yoğunluğa ve yüksek mekanik özelliklere sahip olmalarıdır. Bu nedenle yüksek mekanik dayanım gerektiren uygulamalarda sıklıkla kullanılabilmektedirler. Fiziksel mukavemetinin yanı sıra, kimyasal olarak da inert ve biyouyumlu bir malzeme olan karbon fiber, yüksek termal ve elektriksel iletkenliğe de sahiptir. Bu nedenle karbon fiberlerin polimer, seramik ve karbon matrislerin içine katılarak çeşitli kompozitler üretilmesiyle üstün özelliklere sahip malzeme kombinasyonları yaratılabilmektedir. Böylelikle karbon fiberler, havacılık, otomotiv, tekstil ve inşaat sektörü gibi çok çeşitli alanlarda kullanılabilmektedir.

Geniş uygulama alanları sonucunda artan karbon fỉber talebine karşılık, karbon fiber üretim miktarı da günden güne artmaktadır. 2014 yılında, tüm dünyada karbon fiber üretimi yaklaşık olarak 130000 ton olarak açıklanmıştır. Üretim kapasitesinin en yüksek olduğu ülkeler ise Amerika, Japonya ve Çin'dir [3, 4]. Ayrıca karbon fiber üretimin 2020 yılına kadar 185000 tona ulaşması öngörülmektedir [5]. Fakat, artan karbon fiber talebi ve firmaların mevcut üretim kapasiteleri, piyasadaki karbon fiber fiyatlarında beklenilen oranda azalmaya neden olamamaktadır. Bunun altında yatan temel sorun, karbon fiber maliyetine etki eden en önemli faktörün yüksek hammadde fiyatları olmasıdır. Şekil 2'de de görülebileceği gibi toplam üretim maliyetinin \%51'ini hammadde ücretleri belirlemektedir. $\mathrm{Bu}$ nedenle, karbon fiber üretim maliyetinin düşürülmesi için hedeflenen öncelik hammadde fiyatlarının azaltılması olmalıdır.

Karbon fiber viskoz sıv1 veya yumuşayabilen katı organik hammaddeler kullanılarak üretilir. Günümüzde, ticari karbon fiber üretiminin yarısından fazlası hammadde olarak

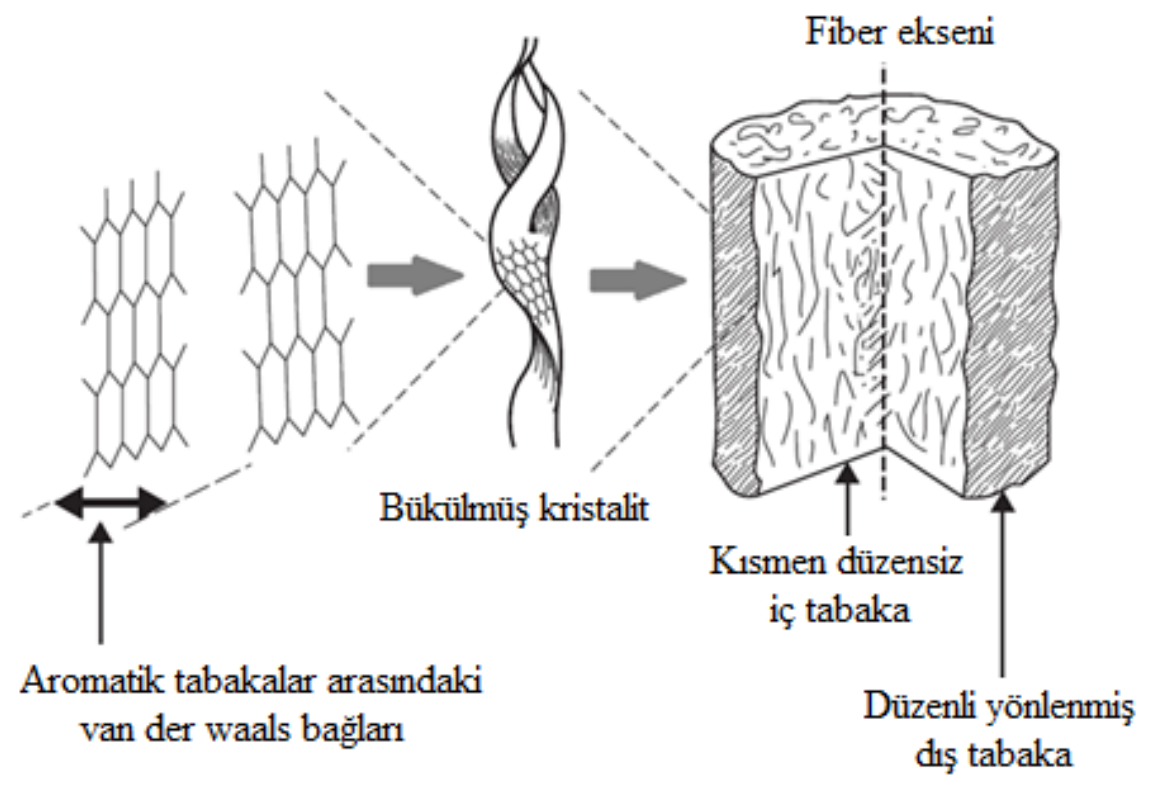

Şekil 1. Karbon fiber yapısı (Structure of carbon fiber) [2]

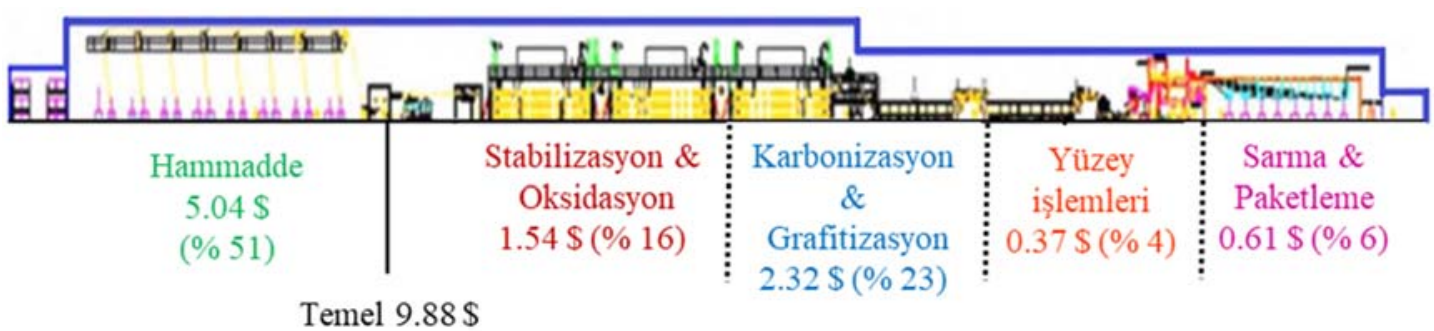

Şekil 2. Karbon fiber üretim maliyetine etki eden faktörler (Factors affecting production cost of carbon fiber) [6] 
PAN'ın (poliakrilonitrilin) işlenmesi ile yapılmaktadır. Fakat PAN'ın detaylı bileşiminin ve sentezinin halen patentlerle korunması ve üretimin çözücü esaslı zor uygulanabilen süreçler gerektirmesinden dolayı, PAN'a alternatif hammadde arayışları sürmektedir. $\mathrm{Bu}$ amaçla poliolefinler ve biyopolimerler gibi yapay veya doğal organik maddelerden karbon fiber üretimi üzerine araştırmalar yürütülmektedir [7]. Karbon fiber üretiminde polietilen $\left[\left(\mathrm{C}_{2} \mathrm{H}_{4}\right)_{\mathrm{n}}\right][8,9]$, fenolik reçineler [10,11], lignin $\left[\left(\mathrm{C}_{31} \mathrm{H}_{34} \mathrm{O}_{11}\right)_{\mathrm{n}}\right][12,13]$, polivinilasetilen $\left[\left(\mathrm{C}_{4} \mathrm{H}_{4}\right)_{\mathrm{n}}\right][14]$, polivinil metil keton $\left[\left(\mathrm{C}_{4} \mathrm{H}_{6} \mathrm{O}\right)_{n}\right][15]$, selüloz $\left[\left(\mathrm{C}_{6} \mathrm{H}_{10} \mathrm{O}_{5}\right)_{n}\right]$, rayon $\left[\left(\mathrm{C}_{18} \mathrm{H}_{32} \mathrm{O}_{16}\right)_{n}\right]$, poliamid $\left[\left(\mathrm{C}_{18} \mathrm{H}_{35} \mathrm{~N}_{3} \mathrm{O}_{3}\right)_{n}\right]$, polivinil alkol $\left[\left(\mathrm{CH}_{2} \mathrm{CHOH}\right)_{n}\right]$, polivinil klorür $\left[\left(\mathrm{C}_{2} \mathrm{H}_{3} \mathrm{Cl}\right)_{\mathrm{n}}\right]$, polivinil asetilen $\left[\left(\mathrm{C}_{4} \mathrm{H}_{4}\right)_{n}\right]$, polibenzimidazol $\left[\left(\mathrm{C}_{20} \mathrm{~N}_{4} \mathrm{H}_{12}\right)_{n}\right]$ gibi çeşitli polimerik maddeler kullanılabilir [16]. Ayrıca, hidrokarbon gazlarından karbon nanotüp üretimindekine benzer olarak, CVD (kimyasal buhar birikimi) yöntemi ile de nano boyutta karbon fiber üretilebilmektedir [17]. Fakat belirtilen hammaddelerin çoğunun ticari açıdan uygulanabilirliğinin sınırlı olmasından dolayı endüstriyel ölçekte fiber üretimi, PAN esaslı ve zift esaslı olmak üzere iki farklı şekilde yapılmaktadır.

PAN esaslı karbon fiberlerin yaklaşık $7 \mathrm{GPa}$ değerine ulaşan yüksek çekme dayanımları olmasına rağmen Young modülü (elastik modülü) zift esaslı fiberlerden düşüktür. Zift esaslı karbon fiberlerin elastik modülü ise yaklaşık $950 \mathrm{GPa}$ 'a ulaşmasına rağmen, çekme dayanımları 3-4 GPa'ın üzerine çıkamamaktadır. Elektriksel ve termal iletkenlik özellikleri bakımından PAN ve zift esaslı karbon fiberler karşılaştırıldığında ise, genellikle zift esaslı karbon fiberlerin performanslarının PAN esaslı fiberlere göre daha iyi olduğu göze çarpmaktadır. PAN ve zift esaslı karbon fiberlerin performanslarının bu derecede farklı olmasının nedeni ise baz1 ziftlerin grafitize edilebilme özelliklerinden kaynaklanmaktadır. Mezofaz, yani anizotropik yapıdaki ziftler, grafenik özellikler gösterdiği için kristalin fazdayken kendiliğinden bir araya gelerek yapısal olarak düzenlenirler. Böylece, fiber çekme işleminde, zift molekülleri sıralanarak ve ardından uygulanan isıl işlem ile grafitik yapı oluşturulabilir [18]. Tablo 1'de bazı izotropik ve mezofaz zift esaslı karbon fiberlerin fiziksel özellikleri ile PAN easlı karbon fiber özellikleri verilmiştir. Karbon fiberlerin hem çekme dayanımı hem de elastik modülü veya iletkenlikleri aynı anda çok fazla yükseltilemeyeceği için, son yıllarda karbon fiber üretimine yönelik çalışmalar fiberlerin kullanılacağ1 uygulamalar göz önünde bulundurularak yapılmaktadır. Ayrıca, üretim maliyetinin düşürülerek, çevre dostu teknolojilerin geliştirilmesi de hedeflemektedir. Bu nedenle, ucuz ve çevre dostu hammadde arayışı ile beraber düşük veya orta fiziksel özelliklere sahip karbon fiberlerin üretimi de araştırmacıların temel amaçlardan biridir. $\mathrm{Bu}$ konular göz önünde bulundurulduğunda zift esaslı karbon fiber üretim çalışmaları ve bu çalışmalardan elde edilen sonuçlar son derece umut vericidir. Sunulan derleme çalışması ile zift esaslı karbon fiber üretim aşamaları özetlenmiştir. $\mathrm{Bu}$ amaçla öncelikle ziftlerin yapısı hakkında genel bilgi verilmiş, ardından üretim aşamaları ve yapıözellik ilişkilerine etki eden parametreler açıklanmıştır.

\section{ZIFTLERIN YAPISI VE BİLEȘIMİ (STRUCTURE AND COMPOSITION OF PITCHES)}

Zift, organik maddelerin pirolizi veya katranın distilasyonu sonucunda elde edilen, oda sicaklığında katı olan ve kimyasal bileşimde aromatik hidrokarbonların ve heterosiklik bileşiklerin bulunduğu kompleks bir karışımdır. Siyah, yapışkan ve oda sıcaklığında katı olan ziftlerin, belirli bir erime sıcaklığı olmayıp, geniş bir yumuşama noktası aralığı vardır. Moleküler ağırlıklarına ve içeriğinde bulunabilen organik maddelere göre ziftlerin yumuşama noktaları $50-350^{\circ} \mathrm{C}$ aralığında değişebilmektedir [2].

Ziftler basitçe büyük aromatik merkezlere sahip yapılar olarak düşünülebilir. $\mathrm{Bu}$ aromatik yapılara uzun alkil zincirleri eklenmesi ile ziftler yumuşayı, çözünebilmektedirler. Yapıda bulunan alifatik hidrojen ise genellikle aromatik halkaya bağlanmış alkil yan zincirlerde bulunmaktadır. Ziftlerdeki aromatik hidrojenin alifatik hidrojene oranı ise ziftin üretildiği hammaddeye bağlı olup, hidrojen aromatikliğinin 0,3-0,9 aralığında olduğu bilinmektedir [2, 20]. Ziftlerin bileşiminin belirlenmesi amacıyla Riggs vd. [21] tarafından yapılan çalışma sonucunda ziftlerin içeriğinde doymuş hidrokarbonlar, naftalenler, polar aromatikler ve asfaltenler olmak üzere dört farklı kimyasal yapının olduğunu belirlenmiştir. Ziftlerin içeriğinde bulunan düşük molekül ağırlığına sahip alifatik hidrokarbonlar, ziftin doymuş hidrokarbon fraksiyonunu

Tablo 1. PAN esaslı karbon fiberler ile mezofaz ve izotropik zift esaslı karbon fiberlerin fiziksel özelliklerinin karşılaştırılması [19]

(Comparison of the physical properties of PAN-based carbon fibers with mesophase and isotropic pitch based carbon fibers)

\begin{tabular}{llllllll}
\hline \multirow{2}{*}{ Hammadde } & $\begin{array}{l}\text { Uygulan } \\
\text { an 1s1l } \\
\text { işlem }\end{array}$ & $\begin{array}{l}\text { Fiber } \\
\text { çap1 } \\
(\mu \mathrm{m})\end{array}$ & $\begin{array}{l}\text { Yoğunl } \\
\mathrm{uk} \\
\left(\mathrm{g} / \mathrm{cm}^{3}\right)\end{array}$ & $\begin{array}{l}\text { Çekme } \\
\text { dayanım1 } \\
(\mathrm{Mpa})\end{array}$ & $\begin{array}{l}\text { Elastik } \\
\text { modülü } \\
(\mathrm{GPa})\end{array}$ & $\begin{array}{l}\text { Elektrik } \\
\text { direnci } \\
\left(10^{-3} \Omega \mathrm{cm}\right)\end{array}$ & $\begin{array}{l}\text { Is1l } \\
\text { genleşme } \\
\text { katsay1s1 } \\
\left(10^{-6} /{ }^{\circ} \mathrm{C}\right)\end{array}$ \\
\hline \multirow{2}{*}{$P A N$} & $\mathrm{~K}$ & 7,0 & 1,74 & 3300 & 230 & 1,6 & $-0,7$ \\
& $\mathrm{G}$ & 6,5 & 1,81 & 2500 & 300 & 0,8 & $-1,2$ \\
\hline \multirow{2}{*}{ Mezofaz zift } & $\mathrm{K}$ & 10 & 1,98 & 3500 & 200 & 13 & $-0,5$ \\
& $\mathrm{G}$ & 10 & 2,18 & 2100 & 520 & 0,5 & -1.2 \\
\hline \multirow{2}{*}{ Izotropik zift } & $\mathrm{K}$ & 14,5 & 1,65 & 720 & 32 & 15 & 1,7 \\
& $\mathrm{G}$ & 14,5 & 1,57 & 600 & 30 & 5 & 1,5 \\
\hline
\end{tabular}

*K: $1300^{\circ} \mathrm{C}$ 'de; G: yaklaşık $2800^{\circ} \mathrm{C}$ sıcaklıkta 1 sıl işleme tabi tutulmuş 
oluştururken; düşük molekül ağırlıklı aromatikler ve doymuş halkalı yapılar da naftalen fraksiyonunu oluşturmaktadır. Polar aromatik yapılar ise daha yüksek molekül ağırlığına sahip olup, daha heterosiklik olma eğilimindedirler. Zender vd. [22] ziftlerin bileşimlerini inceleyerek, belli kimyasal bileşenlerin ziftlerin yapısında bulunduklarını belirlemişlerdir. Tablo 2'de verilen bu bileşenlerin bir çoğunun son derece karmaşık aromatik kimyasal yapılar olduğu görülmektedir.

Ayrıca ziftler, aşağıda belirtildiği üzere değişik karışım yapıları şeklinde de olabilmektedirler. Bunlar:

- Tek fazlı fakat çok ince miselleri içeren kolloidal bir dispersiyon,

- Az da olsa disperse katı maddeleri içeren iki fazlı bir karışım,

- Anizotropik ve izotropik fazlardan oluşan iki fazlı bir karışım,

- Tek bir anizotropik faz içeren karışım (mezofaz),

- İzotropik ve anizotropik fazlarla beraber disperse kat1 maddeleri de içeren çok fazlı karışımlardır [23].

Ziftlerin bileşimlerinde gözlemlenen bu farklılıklar, elde edilen malzemelerin yapısal özelliklerinde önemli değişimlere yol açar. Ziftler, karmaşık yapılarından dolayı ötektik karışımlar gibi davranıp, camsı özellikler gösteriler. Ayrıca, geniş bir sıcaklık aralığında yumuşayabilen ziftler, yumuşadıklarında daha düşük viskoziteye sahip olurlar. Yumuşama noktasından daha yüksek sicaklıklara 1sıtıldıklarında ise bir seri fiziksel ve kimyasal değişim (örneğin yan zincirlerin ve hidrojenin yapıdan ayrılmasından dolayı gerçekleşebilecek polimerizasyon, kondenzasyon, moleküler düzenlenme vb.) göstererek, koklaşırlar [24, 25]. $\mathrm{Bu}$ nedenle hem zift üretiminde hem de ziftlerin işlenmesi sırasında yapı özellikleri belirlenerek, koşullar dikkatlice ayarlanmalidir.

Ziftlerin üretiminde üç aşama önem taşımaktadır. Bunlar, yüksek aromatik içeriğe sahip uygun hammaddenin belirlenmesi, polimerizasyon ve tepkime sonrasında tepkimeye girmeyen moleküllerin ortamdan uzaklaştırılmasıdır [26]. Zift üretimi esnasında kondenzasyon, polimerizasyon, buharlaşma, aromatizasyon ve parçalanma (cracking) gibi tepkimeler meydana gelmektedir. Ziftleri, sentezlendiği hammadde kaynağına göre kömür katranı zifti, petrol zifti ve sentetik ziftler olarak üç alt başlıkta toplamak mümkündür. Kömür katranı zifti ve petrol ziftine literatürde doğal ziftler de denilmektedir. Doğal ziftler, petrol rafineri işlemleri ve kok üretimi sırasında bir yan ürün olarak oluşur. Moleküllerin yönelimine göre ise, izotropik ve anizotropik (mezofaz) olarak ikiye ayrilırlar.

Moleküler yönelim derecesi yüksek olan mezofaz ziftler karbon fiber üretiminde son derece başarılı sonuçlar vermektedir. Mezofaz zift tanımı, ilk olarak 1965 y1lında Brooks ve Taylor [27] tarafından kullanılmıştır. Mezofaz terimi, ziftin katılaşmadan önceki durumunda oluşan küreler ve mozaikler yüzünden kullanılmıştır. Anizotropik mezofaz zift 1sıl çözülmeden sonra belirli aromatik hidrokarbonlara dönüşebilmektedir. Mezofaz zift yüksek ölçüde düzenli, yüksek molekül ağırlıklı bir anizotropik sıvı-kristal sistemi olup, küresel bir şekle sahiptir. Mezofaz ziflerin üretiminde, polimerizasyon esnasında, zift molekülleri kümelenerek bu küresel yapıları oluştururlar. Polimerizasyon devam ettikçe nematik, yani hiçbir yerleşim düzenine sahip olmayan ancak aynı istikamette yönelmeye meyilli moleküller tarafından karakterize edilen bir siv1 kristalin faz, yani mezofaz meydana gelir. Genellikle ziftlerin, koka dönüşümü de mezofaz zift oluşumundan sonra gerçekleşir [28, 29]. Şekil 3'de şematik olarak mezofaz oluşumu özetlenmiştir. Şekil 4'de ise mezofaz ziftin grafitizasyonu esnasında meydana gelen yapısal değişimler verilmiştir $[30,31]$. Düşük sıcaklıklarda, yapıda bulunan farklı şekil ve boyutlardaki mezogen moleküllerinin kümelendiği fakat aslında bu kümelenmenin paralel bir biçimde oluştuğu görülmektedir. Kademeli olarak sıcaklığın arttırılması ile mezogenler, grafen tabakasının yapısına benzer bir şekilde daha az yapısal kusurları içeren bir şekle dönüşür. $\mathrm{Bu}$ yapısal düzenlenme ise grafen tabakası içindeki tek atom hareketi ile gerçekleşir. $1400^{\circ} \mathrm{C}$ 'den $2000^{\circ} \mathrm{C}^{\prime}$ ye kadar isıtılan grafitik yapıda ise kayda değer miktarda katlanma ve bükülmeler gözlemlenebilir. En yüksek grafitizasyon sıcaklıklarına $\left(3200^{\circ} \mathrm{C}\right)$ ulaşıldığında ise yapı polikristalin grafite dönüşür [32, 33]. İzotropik ziftlerin sentezlenmesi ise mezofaz ziftlere kıyasla daha ucuz bir işlemdir. Fakat izotropik ziftler, moleküler yönelim bakımından mezofaz ziftler gibi uniform özellikler göstermedikleri için, izotropik ziftten elde edilen karbonlu malzemelerin grafitizasyonu yapılamaz. Fakat izotropik ziftlerin üretim maliyetlerinin mezofaz ziftlere oranla düşük olması nedeniyle, izotropik ziftler çok yüksek fiziksel dayanıklılık gerektirmeyen uygulamalarda sıklıkla

Tablo 2. Ziftlerin yapısında bulunabilecek kimyasal bileşikler [23]

(Chemical compounds that can be found in the structure of pitches)

Polisiklik aromatik hidrokarbonlar (PAH)

Alkillenmiş polisiklik aromatik hidrokarbonlar

Siklopentan parçacıklarının olduğu polisiklik aromatik hidrokarbonlar

Kısmen hidrojenize olmuş polisiklik aromatik hidrokarbonlar

Oligo-ariller ve origo-aril metanlar

Hetero sübstitiye $\left(\mathrm{NH}_{2}, \mathrm{OH}\right)$ polisiklik aromatik hidrokarbonlar

Polisiklik aromatik hidrokarbonların karbonil türevleri

Polisiklik hetero-aromatik bileşenler (tiyofen, piridin gibi) 

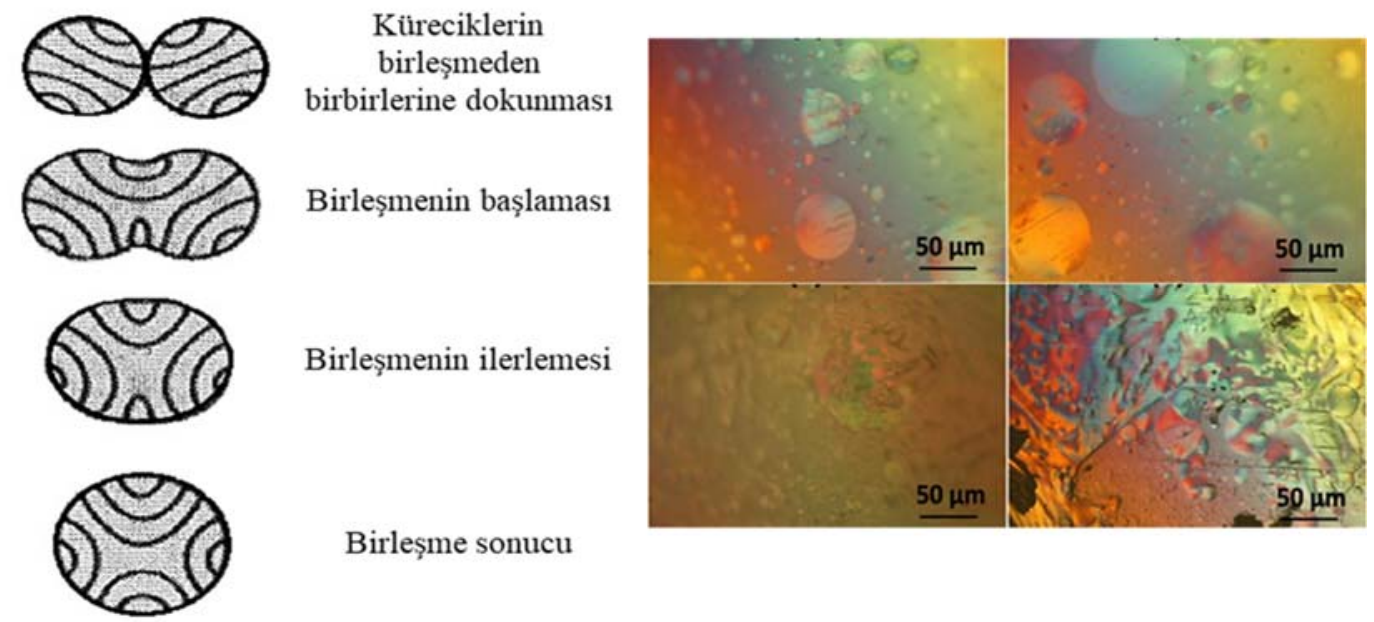

Şekil 3. Ziftlerde küresel mezofaz yapıların oluşumu (Formation of spherical mesophase structures in pitches) [30, 31]

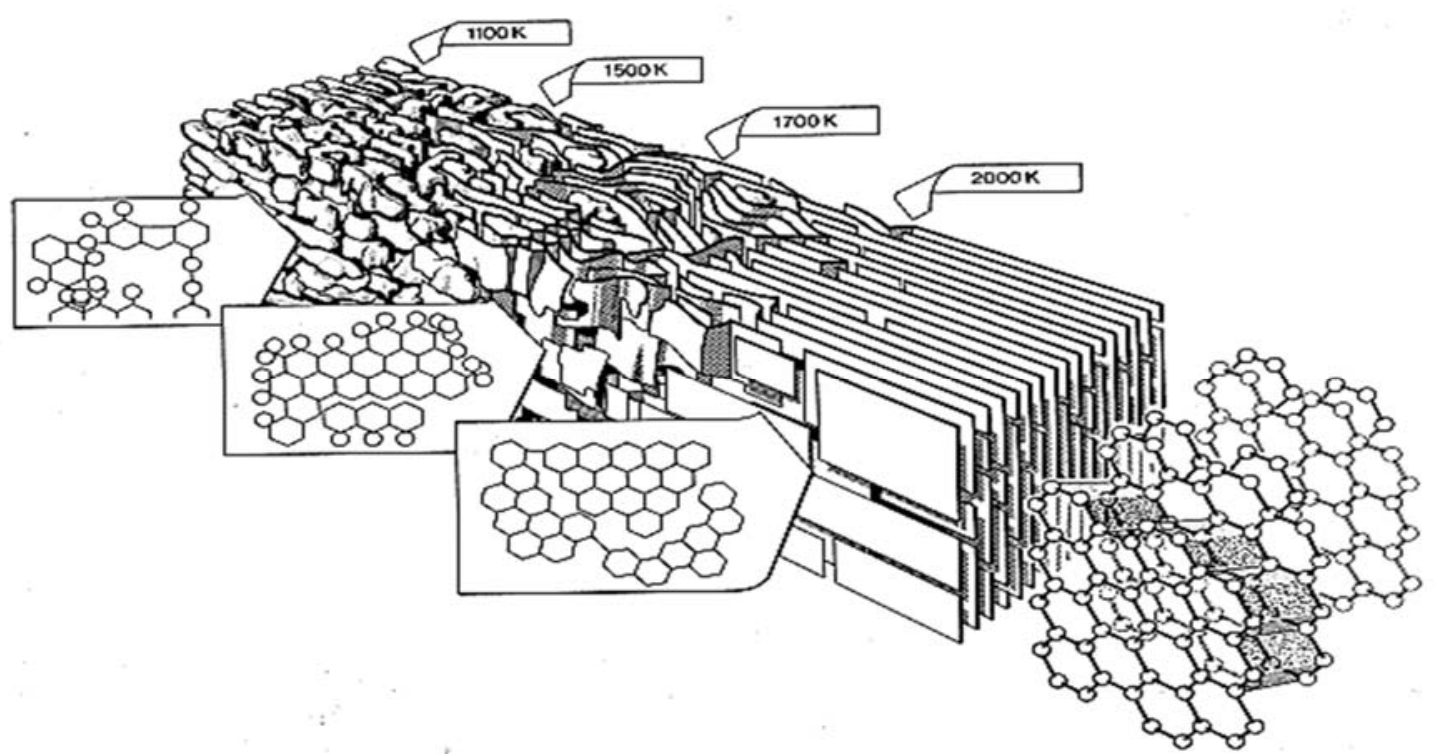

Şekil 4 Mezofazın ısıl işlem ile grafitik karbon yapısına dönüşümü (Transformation of mesophase into graphitic carbon structure by heat treatment) [33]

tercih edilmektedirler. Ziftlerin mezofaz veya izotropik yapıda olması ise üretilen karbon fiberin radyal yöndeki yapısının farklılaşmasına neden olmaktadır. Bu yüzden, düşük dayanıma sahip karbon fiberler izotropik ziftlerden elde edilirken, yüksek dayanıma sahip fiberlerin üretimi için grafitize edilebilen mezofaz ziftlerin kullanımı tercih edilmektedir.

\subsection{Karbon Fiber Üretiminde Kullanılabilecek Ziflerin Taşıması Gereken Özellikler \\ (Properties of Pitches That Can be Used in Carbon Fiber Production)}

Karbon fiber üretiminde kullanılacak mezofaz ve izotropik ziftlerin, fiber çekme işleminde kararlı yapıda olması ve bu işlem esnasında kabarcık oluşumuna ve kopmaya neden olmaması istenilir. Diğer yandan, kullanılan ziftlerin stabilizasyon aşamasında oksijenle tepkimeye girebilecek 1438 kadar reaktif olması da gerekmektedir. $\mathrm{Bu}$ nedenle fiber çekme işleminde, uygulanacak sıcaklığın ziftin yapısının bozulmasını engelleyecek ölçüde düşük olması istenirken, ziftlerin camsı geçiş sıcaklığının da stabilizasyon esnasında fiber yapısının erimesini engelleyecek derecede yüksek olması gerekmektedir.

Bundan dolayı, sadece belirli ziftler fiber çekme ve stabilizasyon koșullarında gereken özellikleri aynı anda sağlayarak karbon fiber üretiminde kullanılabilirler [20]. Karbon fiber üretimine uygun olan ziftlerin aşağıda sıralanan koşulları aynı anda sağlaması gerekmektedir:

- Ziftler, içinde çözünmeden kalan katı partikül maddeleri içermemelidir. Bu durum, fiber çekme işlemini olumsuz etkiler ve üretilen fiberlerin mekanik özelliklerinin kötüleşmesine neden olur. 
- Ziftler, fiber çekme esnasında polimerizasyona uğramamalıdır. Eğer fiber çekme esnasında ziftin polimerizasyonu gerçekleşirse, ziftin viskozitesi değişir. Böyle bir durumda fiber çekme esnasında yapıdan gaz çıkışı gözlemlenir ve fỉber yapısında kusurlar meydana gelir.

- Mezofaz içeriğine sahip ziftlerde, fiber çekme esnasında mezofaz moleküllerinin düzenli bir şekilde sıralanması sağlanmalıdır.

- Fiber stabilizasyonunun hızlı bir şekilde gerçekleştirilmesi için, ziftlerin yumuşama noktası ve camsı geçiş sıcaklığının yeterince yüksek olması gerekmektedir.

- Ziftlerin stabilizasyon esnasinda yeterince reaktif olması, ayrica uygulanan sicaklıkta fiberlerin erimeden, şeklini koruması sağlanmalıdır [34, 35].

\section{ZIFT ESASLI KARBON FIBBERLERINN ÜRETIM AŞAMALARI (PRODUCTION PROCESSES OF PITCH BASED CARBON FIBERS)}

Zift esaslı karbon fiber üretiminde elde edilen son ürün özellikleri üretim şartları ile birlikte ziftlerin yapısı ile doğrudan ilişkilidir. Ziftlerin izotropik veya anizotropik yapıda olması, bileşimi ve moleküler ağırlığı gibi birçok faktör, elde edilen fiberlerin yapısal özeliklerini, grafitizasyon derecesini, fiber çekilebilme yeteneğini ve yüzey kusurlarını doğrudan etkiler. Bu nedenle, zift esaslı karbon fiber üretiminde, istenilen özellikteki ziftlerin sentezi son derece önemlidir. Fiber üretimde uygulanan işlemler ise fiber çekme, stabilizasyon, karbonizasyon (veya grafitizasyon) ve yüzey modifikasyonu işlemleri olarak siralanmaktadir.

\subsection{Fiber Çekme (Fiber Spinning)}

$\mathrm{Bu}$ işlemde zift yumuşama noktasına göre bir ekstruder içinde 1sıtılarak, basınç yardımı ile belli boyuttaki bir püskürtücü başlıktan (nozzle) geçirilir. Ardından eriyik halde kapilerden akan fiber, soğutularak bir bobine sarılır. Fiber çekme işlemi süresince esktruder vidaları arasında katı besleme, eritme ve pompalama olmak üzere 3 farklı bölge oluşur. Giriş kısmında, katı zift eriyik kısmına taşınır ve bu bölgede zift 1sıtılırken, ziftin viskozitesi değişir. Ardından pompalama kısmından eriyik zift kalıp çıkışına doğru itilir. $\mathrm{Bu}$ kısımda, eriyik zift içinde bulunabilecek ve fiber yapısında safsızlık yaratabilecek katı maddelerin ayırımı da son derece önemlidir. Eriyik zift kapiler açıklığından akarken bir yandan uygulanan gerilim ile yapısal olarak düzenlenmeye de başlar. Soğutma kısmında ise fiber şeklinde çekilen zift tekrar katı faza geçerek moleküler yöneliminin artması sağlanır.

Literatürde karbon fiberlerin yapısına fiber çekme koşullarının etkisinin incelendiği birçok çalışma mevcuttur. Örneğin, Hamata vd. [36] fiber çekme sırasında moleküller yönelimin, ziftin viskozitesinin düşük olduğu zaman daha iyi bir sonuç verdiğini belirtmişlerdir. Çünkü fiber çekme işleminde mezogen yapıların özelliklerinin yanı sıra, moleküllerin istenilen yönelime geçerek sıvı kristalin yapıya dönüşmesi beklenilmektedir. Yoon vd. [37] tarafından yapılan çalışmada ise üretilen fiberlerin mikro yapısı ve kesit şekli gibi yapısal özelliklerinin hem ziftin viskoelastik özelliklerine hem de püskürtücü şekli ve boyutu, çekme sıcaklığı ve hızı gibi işlem parametrelerine bağlı olduğu belirlenmiştir. Fiber çekme sırasında fiber yapısına etki eden en önemli parametrenin uygulanan işlem sicaklığı olduğu bilinmektedir. Fiber çekme sıcaklığı, kullanılan ziftin yumuşama noktası ile doğrudan ilişkilidir. Fiber çekme sıcaklığının çok düşük olması durumunda, zift tamamen eriyemeyeceği için fiberin püskürtücüden dışarı çıkış1 sağlanamaz. Sıcaklığın gerekenden çok yüksek olmasında ise işlem sırasında zift fiber şeklinde değil de damla damla akar ve fiber yapısı sağlayamaz. Belli bir sürede, belli bir püskürtücü çıkış boyutunda fiber halinde sarılan örnek miktarı ise uygulanan basınca bağlıdır. Diğer yandan, üretilen fiberlerin çapı, hem basınca hem de fiber sarma hızı ile değişir. Bobin sarma hızının çok düşük olması durumunda filament oluşumu için gereken gerilim sağlanamazken, çok hızlı olması da işlem sırasında sarılan fiberlerde kırıklar oluşmasına neden olur. Püskürtücü delik boyutu ise fiber çapını ve uygulanması gereken basıncı belirleyen bir parametredir. Fiber sarma hızı sabit kalmak koşuluyla püskürtücü çıkış çapı arttırılırsa, ziftin fiber şeklini alabilmesi için gereken basıncın da azaltılması gerekmektedir [38].

\subsection{Stabilizasyon (Stabilization)}

Karbon fiber üretiminde stabilizasyon aşamas1, üretilecek fiberin şeklinin ve yapısının değişmemesini sağlayacak koşullarda gerçekleştirilmelidir. Ayrıca, stabilizasyonun karbon fiber üretimindeki en yavaş adım olması, üretilen fiberlerin maliyetini büyük ölçüde etkilemektedir. $\mathrm{Bu}$ nedenle fiberlerin stabilizasyon koşulları dikkatlice ayarlanarak, en uygun koşulların belirlenmesi gerekmektedir.

Yapıya oksijen difüzyonunun olduğu ve oksidatif tepkimelerin gerçekleştiği stabilizasyon sırasında, stabilizasyon derecesi ve h1z1, üretilen karbon fiberlerin mekanik dayanımını doğrudan etkilemektedir. Stabilizasyon esnasında yapıda bulunan alifatik grupların daha çok etkilendiği ve çeşitli oksijen fonksiyonel grupların yapıya katıldığı bilinmektedir [29].

Stabilizasyon işlemi esnasında termoplastik yapıda olan fiberler, termoset bir yapıya dönüştürülür. $\mathrm{Bu}$ nedenle ziftlerin camsı geçiş sıcaklığının arttırılması ve yapıdan düşük molekül ağırlıklı bileşenlerin ayrılması için çözücü ekstraksiyonu veya süperkritik çözücü ekstraksiyonu gibi işlemler de fiber çekme öncesinde uygulanabilmektedir. Stabilizasyon işlemine etki eden temel faktörler, ziftin yapıs1, stabilizasyon sirasinda uygulanan sicaklik, 1sitma hız1, kullanılan gaz ve stabilizasyon süresi olarak sıralanabilir [20]. Stabilizasyon esnasında fiberin yüksek sicaklıklara kadar 1sitılması, ziftin yapısında bulunan oksijen içeren aromatik grupların bozunmasına neden olur. Bunun nedeni, stabilizasyon esnasinda oksijenasyon, oksidatif 
dehidrojenasyon ve yanma gibi kimyasal tepkimelerin gerçekleşmesidir. Zift yapısında bulunan oksijen içeren grupların bozunması sirasinda da fiber yapısında istenmeyen kusurlar meydana gelebilir. Bu nedenle stabilizasyonda hizlı 1sıtma yapılması, gerçekleşen oksidasyon işleminin daha hızlı olmasına ve dolayısıyla yapıda kusurların ortaya çıkmasına neden olur. Karbon fiberlerin stabilizasyonunun gerekenden az yapılması durumunda fiber şekli deformasyona uğrayıp, oksidasyon tepkimeleri hızlanır. Böylece bir sonraki aşama olan karbonizasyon sırasında oksijen fonksiyonel gruplar bozunabilir. Bu bozunmalar, fiberlerin iç ve dış yüzeylerinde yapısal kusurlar oluşturup, fiberlerin mekanik özelliklerini olumsuz yönde etkiler. Ayrıca, stabilizasyon işleminin gereğinden fazla yapılması da mezofaz ziftlerde mezogen moleküllerinin boyutlarının gereğinden fazla büyümesine neden olur. Böyle bir durumda moleküller düzenli sıralanamaz [29] ve fïberlerin özellikleri kötüleşir [32, 39]. Bu amaçla stabilizasyonun yeterli miktarda yapılabilmesi için en uygun koşullar belirlenmelidir.

Stabilizasyon sırasında göz önünde bulundurulması gereken diğer faktörler; fiber ekseni boyunca gerçekleşen oksijen difüzyon hızı, gerçekleşen tepkimelerin hızı ve zift yapısında bulunan reaktif bölgelerdir. Fiber çap1 boyunca yapıya oksijen giriş gradyanının değişmesi durumunda gerçekleşen kütle transfer hızı etkilenir. Stabilizasyon sıcaklığı, 1sıtma hızı, süre, fiber çapı ve oksitleyici gaz akış hızı bu aşamada oksijen difüzyonunu etkileyen temel parametreler olarak sıralanabilir. Yüksek sıcaklık ve kısa stabilizasyon süreleri ise oksijen alım hızını arttırmaktadır. Yüksek 1sıtma hızları uygulanması durumunda fiber yüzeyinden merkezine doğru daha yüksek bir gradyan oluşmaktadır. Fakat, düşük ısıtma hızları kullanılması ile fiber ekseni boyunca gerçekleşecek oksijen dağılımı daha homojen bir şekilde gerçekleşmektedir [40-42]. Zift esasl1 karbon fiber üretiminde, ziftlerin oksijen içeriği stabilizasyon aşaması için büyük önem taşımaktadır. $\mathrm{Bu}$ nedenle, karbon fiber üretiminde kullanılacak ziftlerin elementel oksijen içeriğinin her zaman düşük olması istenilmektedir. Çünkü yüksek oksijen içeren ziftler kullanılması durumunda, zift içine oksijen difüzyonu ve karbonizasyon verimi azalır [7, 29].

\subsection{Karbonizasyon ve Grafitizasyon \\ (Carbonization and Graphitization)}

Stabilizasyon sonrasında fiberlerin içerdiği karbon miktarını arttırmak amacıyla inert atmosferde 1sıtılması işlemine karbonizasyon adı verilmektedir. 1000 veya $1100^{\circ} \mathrm{C}$ 'ye kadar sıcaklıklarda yapılan işlemde, sıcaklığının $3000^{\circ} \mathrm{C}$ 'lere kadar çıkarılması ile karbon yapısı daha düzenli bir hale gelerek grafitize olabilir. Bu nedenle bu yüksek sıcaklıklara kadar yapılan karbonizasyon işlemleri grafitizasyon olarak adlandırılır [20]. Karbonizasyonu yapilan fiberlerin bir önceki üretim aşamasında yeterli derecede stabilizasyonu sağlanabilmiş ise, karbonizasyon esnasında uygulanan 1sıtma hızından son ürün özellikleri daha az etkilenmektedir. Fakat karbonizasyon sırasında gerçekleşebilecek ani sıcaklık artışlarının da kontrol edilmesi gerekmektedir. Özellikle, $400-750^{\circ} \mathrm{C}$ sicaklık aralığında fiber yapısından su buharı, karbon dioksit, karbon monoksit ve metan gibi bileşikler ayrıldığı için, ani sıcaklık artışları fiber üzerinde yüzey kusurlarının oluşmasına neden olabilmektedir [43].

Karbonizasyon, temelde aromatik moleküllerin büyümesi ve bu moleküllerin polimerizasyonu olarak ifade edilebilir. Karbonizasyon mekanizması son derece karmaşık olmasına rağmen gerçekleşen başlıca tepkimeler beş ana grupta sinıflandırılarak özetlenebilir. Bunlar:

- Aromatik C-C ve C-H bağlarının ayrılarak serbest radikallerin oluşumu,

- Moleküler düzenlenme tepkimeleri,

- Termal polimerizasyon,

- Aromatik kondenzasyon,

- Zincir yapısına bağlı yan grupların ve hidrojenin yapıdan ayrilmasidir [43].

Belirtilen tepkimeler gerçekleşirken, düşük molekül ağırlığına sahip uçucu bileşikler yapıdan uzaklaşır ve yapıda elementel karbon miktarı artar. Yapılan araştırmalarda [4346] karbonizasyon esnasında $300-500^{\circ} \mathrm{C}$ sıcaklık aralığında hidroksil, karbonil ve doymuş hidrokarbonların yapıdan ayrıldığ 1 belirlenirken; $500-800^{\circ} \mathrm{C}$ arasında ise hidrojenin açığa çıktığı ve aromatik kondenzasyon tepkimelerinin meydana geldiği saptanmıştır.

Grafitizasyon işleminde ise grafitik tabakalar, 3 boyutlu bir düzenlenme ile kristalin grafit yapısına yaklaşır. Fakat grafitizasyon işlemi önceden de belirtildiği gibi sadece mezofaz ziftten elde edilen karbon fiberlere uygulanabilmektedir. Isıl işlem sıcaklığının arttırılması ile grafitizasyon derecesi arttırılarak fiberlerin mekanik özellikleri iyileştirilir. Fakat grafitizasyon işlemi sırasında ziftlerin içerebileceği azot, kükürt gibi atomları içeren moleküllerin yapıdan ayrılması ile grafitik yapıda da bozulmalar gözlemlenebilir. Grafitizasyon esnasında fiberlere uygulanabilecek maksimum sıcaklığın, karbonun buhar basincı ve kullanılan grafitizasyon firınlarının uzun dönemde işletilebilirliği göz önünde bulundurularak yaklaşık $3100^{\circ} \mathrm{C}^{\prime}$ de tutulması sağlanmalıdır [20].

\subsection{Yüzey Modifikasyonu (Surface Modification)}

Zift esaslı fiber üretiminde, üretilen fiberlerin kompozit yapılar içinde kullanılabilmesi ve yapıdaki aşınmaların engellenmesi (veya azaltılabilmesi) için fiberlerin yüzeyleri çeşitli yöntemlerle modifiye edilmektedir. Karbon fiberler, dış tarafinda bulunan grafitik tabakadan dolayı, yüzey enerjisini kendiliğinden en aza indirgeyebilecek bir yapıya sahiptirler. Uygulanan 1sıl işlemler ise yüzey kusurlarını azaltarak, reaktif olmayan grafitik yüzeyini daha da düzenli bir hale getirir. Sonuç olarak, üretilen fiberlerin ıslanabilirlik özelliği az olur ve bu nedenle düz yüzeylerde kimyasal bağların kurulması zorlaşır. Belirli uygulamalar için fiber yüzeyi özel oksidatif işlemler ile pürüzlü hale getirilip, kompozit yapılarda fazların birbirine daha iyi tutunması sağlanabilmektedir. Ayrıca, fiber yüzeyinde çeşitli 
fonksiyonel gruplar oluşturularak da fiberin kimyasal bağ kurma kabiliyeti sağlanır ve/veya arttırılır. Karboksilik, kinolik, fenolik ve hidroksilik gibi çeşitli yüzey fonksiyonel grupların fiber yüzeyinde oluşturulması ile fabrikasyon esnasında karbon fiberlerin 1slanabilirlik özellikleri de iyileştirilebilmektedir [20]. Ayrıca oksijen içeren fonksiyonel grupların oluşumu için karbon fiberlerin nitrik asit [47], hidrojen peroksit [48] gibi kimyasallar ile işlenmesi veya anodik oksidasyon $[49,50]$ yapılması gibi yöntemler de uygulanmaktadır.

Günümüzde yürütülen zift esaslı karbon fiber üretim çalışmaları incelendiğinde, bu çalışmaların öncellikle üretim maliyetlerini azaltmak amacıyla, alternatif zift kaynakları geliştirmeye odaklandığı görülmüştür. $\mathrm{Bu}$ amaçla farklı kömür ve petrol, fraksiyonları ile polimerlerin zift üretiminde kullanımı üzerine çalışmalar [51, 52] yürütülmektedir. Ayrıca farklı hammaddelerden karışımlar hazırlanarak hibrit zift üretimi çalışmaları da yapılmaktadır. Naskar vd. [55], Prauchner vd. [56, 57], Ma vd. [58] gibi araştırmacılar ise karbon fiber üretiminde fosil kaynaklara alternatif olabilecek yenilenebilir biyokütle kaynaklarını kullanmayı hedeflemektedir. $\mathrm{Bu}$ araştırmalarda, üretim maliyetini azaltmanın yansıra, elde edilen fiber özelliklerinin ticari karbon fiberler ile karşılaştırılabilecek derecede iyi olması da beklenilmektedir. Karbon fiber üretimi boyunca stabilizasyon işleminin en yavaş gerçekleştirilmesi gereken adım olması ise; stabilizasyon değişkenleri hakkında optimizasyon çalışmaları yapılmasını gerektirmektedir. Örneğin, Kim vd. [59], Jang vd. [60] gibi araştırmacılar tarafından stabilizasyon sürecini incelenerek, bu aşamanın son ürün özelliklerine etkileri saptanmıştır. Ayrıca Ko vd. [61] ile Yue vd. [62) tarafindan yayımlanan çalışmalar, uygulanabilecek farklı stabilizasyon yöntemlerine örnekler teşkil etmektedir. Karbon fiber üretimindeki karbonizasyon işleminin [63], kinetik mekanizmaların [64], yüzey modifikasyonunun [65] incelenmesi gibi farklı üretim aşamaları hakkındaki çalışmalar da ürün özelliklerinin geliştirilmesi için stabilizasyon ile birlikte yürütülmelidir. Zift sentezi ve üretim aşamalarının incelenmesinin yanı sıra, zift ve karbon fiberlerin farklı kompozitlerde kullanımı [6668] ile kompozitlerin çeşitli fiziksel ve kimyasal özelliklerinin geliştirilmesi $[69,70]$ de bu alanda sürdürülen bir başka çalışma alanı olarak sıralanabilir. Ayıca, zift ve karbon fiber içeren kompozitlerin elektrokimya gibi çeşitli alanlarda kullanılabilirliğini $[71,72]$ inceleyen çalışmaların son yıllarda umut verici sonuçlara ulaştığı bilinmektedir.

\section{SONUÇLAR (CONCLUSIONS)}

Artan endüstriyel karbon fiber talebini karşılamak için daha ucuz, verimli hammaddelerin incelenmesi ve üretim süreçlerinin geliştirilmesi bir zorunluluktur. Özellikle çok yüksek mekanik özellikler gerektirmeyen genel amaçlı fiberlerin üretiminin zift esaslı süreçlere kaydırılması ile hammadde temininde esneklik sağlanması ve maliyetlerin azaltılması mümkündür. Ayrıca, petrol ve kömür gibi fosil kaynakların güvenilirliği de göz önünde bulundurulduğunda karbon fiber üretiminde kullanılmak üzere alternatif kaynakların araştırılması ve ürün özelliklerinin geliştirilmesine devam edilmelidir. Günümüzde, farklı zift üretim yöntemleri ve farklı hammaddelerinin zift üretimde uygulanabilirliği ile sadece karbon fiber üretimi değil, karbon köpük, karbon elektrot gibi farklı karbon esaslı malzemeler de geliştirilmektedir. Özellikle mezofaz ziftin kullanımı ile mikro yapının kontrol edilerek üretilen karbonlu malzemelerin mekanik dayanımları arttırılması ve/veya daha iyi termal ve elektriksel özelliklere sahip olması mümkündür.

Karbon fiber üretiminde, zift eldesi çalışmalarının yanı sıra, fiber çekme, stabilizasyon, karbonizasyon/grafitizasyon ve yüzey işlem süreçlerinde farklı yaklaşımlar kullanılarak, ürün kalitesini ve enerji verimliliğini iyileştirmeyi hedef alan çalışmalar, üzerine yoğunlaşılması gereken başlıca konulardır. Ayrıca karbon fiberlerin polimer, seramik ve karbon-karbon kompozit yapılarına katılmasıyla üretilen malzemelere potansiyel kullanım alanlarının yaratılmasına yönelik çalışmalar da yapılmalıdır.

Sonuç olarak, teknolojik, ekolojik ve ekonomik dengeyi sağlayabilecek şekilde, karbon fiber piyasasına hakim olan PAN esaslı karbon fiber üretimine paralel bir şekilde yürütülebilecek zift esaslı karbon fiber üretiminin geliştirilmesi endüstriyel bakımdan son derece önem taşımaktadır.

\section{TEŞEKKÜR (ACKNOWLEDGMENT)}

Sürdürülen çalışmayı BİDEB 2214-A programı ile destekleyen TÜBİTAK'a ve deneyimlerini paylaşan Kyushu Üniversitesi Karbonlu Malzemeler Bilimi Laboratuvarı'na (Laboratory of Carbon Materials Science) teşekkür ederiz.

\section{KAYNAKLAR (REFERENCES)}

1. Hull D., Clyne T.W., An Introduction to Composite Materials, Cambridge University Press. Macmillan, New York, A.B.D.,1981.

2. Somiya S., Handbook of Advanced Ceramics: Materials, Applications, Processing, and Properties. Elsevier Academic press, Waltham, A.B.D., 2013.

3. Global and China Carbon Fiber Industry Report, http://www.rnrmarketresearch.com/global-and-chinacarbon-fiberindustry-report-2014-2017-marketreport.html. Erişim tarihi 15.02.2016.

4. Statistista, The Statistics Portal, http://www.statista.com/statistics/380549/leadingcountries-by-carbon-fiber-production-capacity/. Erişim tarihi: 20.09.2016.

5. Roberts T., The Carbon Fiber Industry worldwide 20112020, Materials Technology Publications, Watford, 2011.

6. Warren C.D., Low cost carbon fiber overview. Oak Ridge National Laboratory, Oak Ridge, Tennessee, A.B.D., 2011

7. Özsin G., Farklı Organik Atıklardan Zift Esaslı Karbon Fiber Üretimi ve Karakterizasyonu, Doktora tezi, Anadolu Üniversitesi. Fen Bilimleri Enstitüsü, Eskişehir, 2017. 
8. Zhang D., Sun Q., Structure and properties development during the conversion of polyethylene precursors to carbon fibers, Journal of Applied Polymer Science, 62 (2), 367-373, 1996.

9. Hulicova D., Oya A., The polymer blend technique as a method for designing fine carbon materials, Carbon, 41 (7), 1443-1450, 2003.

10. Oya A., Kasahara N., Preparation of thin carbon fibers from phenol-formaldehyde polymer micro-beads dispersed in polyethylene matrix, Carbon, 38 (8), 11411144, 2000.

11. Guo Z., Liu Z., Ye L., Ge K., Zhao T., The production of lignin-phenol-formaldehyde resin derived carbon fibers stabilized by BN preceramic polymer, Materials Letters, 142, 49-51, 2015.

12. Nar M., Rizvi H.R., Dixon R.A., Chen F., Kovalcik A., D'Souza N., Superior plant based carbon fibers from electrospun poly-(caffeyl alcohol) lignin, Carbon, 103, 372-383, 2016.

13. Imel A.E., Naskar A.K., Dadmun M.D., Understanding the Impact of Poly (ethylene oxide) on the Assembly of Lignin in Solution toward Improved Carbon Fiber Production, ACS Applied Materials \& Interfaces, 8 (5), 3200-3207, 2016.

14. Mavinkurve A., Visser S., Pennings A.J., An initial evaluation of poly (vinylacetylene) as a carbon fiber precursor. Carbon, 33 (6), 757-761, 1995.

15. Krumpfer J.W., Giebel E., Frank E., Mueller A., Ackermann L.M., Tironi C.N., Mourgas G., Unold J., Klapper M., Buchmeiser M.R., Müllen K., Poly (methyl vinyl ketone) as a Potential Carbon Fiber Precursor. Chemistry of Materials, 29 (2), 780-788, 2017.

16. Park S.J., Carbon fibers. Springer, Hollanda, 2015.

17. Bayat N., Rezaei M., Meshkani F., Hydrogen and carbon nanofibers synthesis by methane decomposition over $\mathrm{Ni}-\mathrm{Pd} / \mathrm{Al}_{2} \mathrm{O}_{3}$ catalyst, International Journal of Hydrogen Energy, 41 (12), 5494-5503, 2016.

18. Zhang J., Terrones M., Park C.R., Mukherjee R., Monthioux M., Koratkar N., Kim Y.S., Hurt R., Frackowiak E., Enoki T., Chen Y., Bianco A., Carbon science in 2016: status, challenges and perspectives, Carbon, 98 (70), 708-732, 2016.

19. Inagaki M., Kang F., Materials Science and Engineering of Carbon: Fundamentals. Butterworth-Heinemann, Waltham, A.B.D., 2014.

20. Kelly A., Zweben C.H., Comprehensive Composite Materials, Elsevier, A.B.D., 2000.

21. Riggs D.M., Shuford R.J., Lewis R.W., Graphite fibers and composites. In Handbook of composites, Springer, A.B.D., 1982

22. Zander M., On the composition of pitches, Fuel, 66 (11), 1536-1539, 1987.

23. Almugerhiy A.A., Preperation and Characterization of Göynük Oil Shale Derived Pitch Precursors For Production of Carbon Matarials, Doktora Tezi, İstanbul Teknik Üniversitesi, Fen Bilimleri Enstitüsü, İstanbul, 1998.

24. El-Akrami H.A. Preparation and Characterization of Avgamasya Asphaltite and Raman-Dinçer Crude Oil Derived Pitches For Production of Stabilized Fiber,
Doktora Tezi, İstanbul Teknik Üniversitesi, Fen Bilimleri Enstitüsü, İstanbul,1998.

25. Gül A., Mesophase Pitch Derived Graphitic Carbon Foam. Yüksek Lisans Tezi, İstanbul Teknik Üniversitesi, Fen Bilimleri Enstitüsü, İstanbul, 2005.

26. Özel M.Z., Bartle K.D., Production of mesophase pitch from coal tar and petroleum pitches using supercritical fluid extraction, Turkish Journal of Chemistry, 26 (3), 417-424, 2002.

27. Brooks J.D., Taylor G.H., The formation of graphitizing carbons from the liquid phase. Carbon, 3 (2), 1965.

28. Ekşilioğlu A., Effect of Temperature, Solvent Type and Additives On The Properties of Mesophase Pitch Based Carbon Foam, Yüksek Lisans Tezi, İstanbul Teknik Üniversitesi, Fen Bilimleri Enstitüsü, İstanbul,2004.

29. Kim, B.J.,Study of Isotropic Pitch Based Carbon Fiber for Automotive Body. Doktora Tezi, Kyuhu University, Institute for Materials Chemistry and Engineering, Fukuoka, 2014.

30. Figueiredo J.L., Bernardo C., Baker R.T.K., Hüttinger K.J., Carbon Fibers, Filaments and Composites, Springer Science \& Business Media, Hollanda, 2013.

31. Kumar S., Srivastava M., Mesophase formation behavior in petroleum residues, Carbon Letters, 16 (3), 171-182, 2015.

32. Mochida I., Korai Y., Ku C. H., Watanabe F., Sakai Y., Chemistry of synthesis, structure, preparation and application of aromatic-derived mesophase pitch, Carbon, 38(2), 305-328, 2000.

33. Marsh H., Martínez-Escandell M., Rodríguez-Reinoso F., Semicokes from pitch pyrolysis: mechanisms and kinetics. Carbon, 37(3), 363-390, 1999.

34. Fitzgerald R.L., Novel Applications of Carbon Fiber for Hot Mix Asphalt Reinforcement and Carbon-Carbon Pre-forms, Yüksek Lisans Tezi, Michigan Technological University Michigan, 2000.

35. Peebles Jr.L. H., Carbon fibers, formation, structure and properties. CRC Press, Inc, Boca Raton, A.B.D., 1995.

36. Hamada T., Furuyama M., Sajiki Y., Tomioka T., Endo M., Preferred orientation of pitch precursor fibers, Journal of Materials Research, 5 (06), 1271-1280, 1990.

37. Yoon S.H., Korai Y., Mochida I., Spinning characteristics of mesophase pitches derived from naphthalene and methylnaphthalene with $\mathrm{HF} / \mathrm{BF}_{3}$, Carbon, 31 (6), 849-856, 1993.

38. Díez N., Álvarez P., Santamaría R., Blanco C., Menéndez R., Granda M., Optimisation of the meltspinning of anthracene oil-based pitch for isotropic carbon fibre preparation, Fuel Processing Technology, 93 (1), 99-104, 2012.

39. Matsumoto T., Mochida I., A structural study on oxidative stabilization of mesophase pitch fibers derived from coal tar, Carbon, 30 (7), 1041-1046, 1992.

40. Mochida I., Toshima H., Korai Y., Hino T., Oxygen distribution in the mesophase pitch fibre after oxidative stabilization, Journal of materials science, 24 (2), 389394, 1989.

41. Mochida I., Toshima H., Korai Y., Matsumoto T., Control of molecular orientations in mesophase pitch- 
based carbon fibre by blending PVC pitch, Journal of materials science, 24 (1), 57-62, 1989.

42. Matsumoto T., Mochida I., Oxygen distribution in oxidatively stabilized mesophase pitch fiber, Carbon, 31 (1), 143-147, 1993.

43. Tekinalp H., Pitch Based Carbon Fibers: The Effect of Precursor Composition on Pore Structure. Doktora Tezi, South Carolina: Clemson University, Graduate School, Clemson, 2011.

44. Edie D.D., The effect of processing on the structure and properties of carbon fibers, Carbon, 36 (4), 345-362, 1998.

45. Yang C.Q., Simms J.R., Infrared spectroscopy studies of the petroleum pitch carbon fiber-I. The raw materials, the stabilization, and carbonization processes, Carbon, 31 (3), 451-459, 1993.

46. Wu X., Gallego N.C., Contescu C.I., Tekinalp H., Bhat V.V., Baker F.S., Thies M.C., The effect of processing conditions on microstructure of Pd-containing activated carbon fibers, Carbon, 46 (1), 54-61, 2008.

47. Woodhead A.L., de Souza M.L., Church J.S., An investigation into the surface heterogeneity of nitric acid oxidized carbon fiber, Applied Surface Science, 401, 79-88, 2017.

48. Jung M.J., Park M.S., Lee S., Lee Y.S., Effect of E-beam Radiation with Acid Drenching on Surface Properties of Pitch-based Carbon Fibers, Applied Chemistry for Engineering, 27 (3), 319-324, 2016.

49. Fukunaga A., Ueda S., Anodic surface oxidation for pitch-based carbon fibers and the interfacial bond strengths in epoxy matrices, Composites Science and Technology, 60 (2), 249-254, 2000.

50. Yumitori S., Nakanishi Y., Effect of anodic oxidation of coal tar pitch-based carbon fibre on adhesion in epoxy matrix: Part 1. Comparison between $\mathrm{H}_{2} \mathrm{SO}_{4}$ and $\mathrm{NaOH}$ solutions, Composites Part A: Applied Science and Manufacturing, 27 (11), 1051-1058, 1996.

51. Li X., Zhu X. Q., Okuda K., Zhang Z., Ashida R., Yao H., Miura K. (2017). Preparation of carbon fibers from low-molecular-weight compounds obtained from lowrank coal and biomass by solvent extraction., New Carbon Materials, 32 (1), 41-47, 2017.

52. Yang J., Nakabayashi K., Miyawaki J., Yoon S.H., Preparation of isotropic pitch-based carbon fiber using hyper coal through co-carbonation with ethylene bottom oil, Journal of Industrial and Engineering Chemistry, 34, 397-404, 2016.

53. Kim M.S., Lee D.H., Kim C.H., Lee Y.J., Hwang J.Y., Yang C.M., Yang K.S., Shell-core structured carbon fibers via melt spinning of petroleum-and woodprocessing waste blends, Carbon, 85, 194-200, 2015.

54. Yang J.X., Nakabayashi K., Miyawaki J., Yoon S.H., Preparation of isotropic spinnable pitch and carbon fiber by the bromination-dehydrobromination of biotar and ethylene bottom oil mixture, Journal of Materials Science, 52 (2), 1165-1171, 2017.

55. Naskar A.K., Akato K.M., Tran C.D., Paul R.M., Dai X., Low cost bio-based carbon fiber for high temperature processing (No. ORNL/TM-2017/83). Oak Ridge National Laboratory (ORNL), Oak Ridge, TN (United
States). Center for Nanophase Materials Sciences (CNMS); Carbon Fiber Technology Facility (CFTF), 2017.

56. Prauchner M.J., Pasa V., Otani C., Otani S., de Menezes S. (2004). Eucalyptus tar pitch pretreatment for carbon material processing. Journal of Applied Polymer Science, 91 (3), 1604-1611, 2004.

57. Prauchner M.J., Pasa V.M.D., Otani S., Otani C., Biopitch-based general purpose carbon fibers: Processing and properties. Carbon, 43(3), 591-597, 2005.

58. Ma X., Zhao G., Variations in the microstructure of carbon fibers prepared from liquefied wood during carbonization. Journal of Applied Polymer Science, 121 (6), 3525-3530, 2011.

59. Kim B.J., Kotegawa T., Eom Y., An J., Hong I.P., Kato O., Nakabayashi K., Miyawaki J., Kim B.C., Mochida I., Yoon S.H., Enhancing the tensile strength of isotropic pitch-based carbon fibers by improving the stabilization and carbonization properties of precursor pitch. Carbon, 99, 649-657, 2016.

60. Jang S.Y., Ko S., Jeon Y.P., Choi J., Kang N., Kim H.C., Joh H.I., Lee S., Evaluating the stabilization of isotropic pitch fibers for optimal tensile properties of carbon fibers. Journal of Industrial and Engineering Chemistry, 45, 316-322, 2017.

61. Ko S., Choi J.E., Lee C.W., Jeon Y.P., Modified oxidative thermal treatment for the preparation of isotropic pitch towards cost-competitive carbon fiber. Journal of Industrial and Engineering Chemistry, 54, 252-261, 2017.

62. Yue Z., Liu C., Vakili A., Solvated mesophase pitchbased carbon fibers: thermal-oxidative stabilization of the spun fiber. Journal of Materials Science, 13 (52), 8176-8187, 2017.

63. Kim J.D., Roh J.S., Kim M.S., Effect of carbonization temperature on crystalline structure and properties of isotropic pitch-based carbon fiber. Carbon Letters, 21, 51-60, 2017.

64. Govorov A., Galiguzov A., Tikhonov N., Malakho A., Rogozin A., Study of Different Types of Carbon Fiber Oxidation Kinetics. Refractories \& Industrial Ceramics, 56 (6), 605-609, 2016.

65. Naito K., Effect of Hybrid Surface Modifications on Tensile Properties of Polyacrylonitrile-and Pitch-Based Carbon Fibers. Journal of Materials Engineering \& Performance, 25 (5), 2074-2083, 2016.

66. Bhagat A.R., Mahajan P., Characterization and damage evaluation of coal tar pitch carbon matrix used in Carbon/Carbon composites. Journal of Materials Engineering and Performance, 9 (25), 3904-3911, 2016.

67. Asano K., Thermal expansion behaviour of squeeze-cast aluminium matrix composites reinforced with PAN-and Pitch-based carbon fibres. International Journal of Cast Metals Research, 1-9, 2017.

68. Martin A., Addiego F., Mertz G., Bardon J., Ruch D., Pitch-Based Carbon Fibre-Reinforced PEEK Composites: Optimization of Interphase Properties by Water-Based Treatments and Self-Assembly. Journal of 
Material Sciences and Engineering, 6 (308), 2169-0022, 2016.

69. Noh Y.J., Kim S.Y., Synergistic improvement of thermal conductivity in polymer composites filled with pitch based carbon fiber and graphene nanoplatelets. Polymer Testing, 45, 132-138, 2015.

70. Mun S.Y., Lim H.M., Lee D.J., Thermal conductivity of a silicon carbide/pitch-based carbon fiber-epoxy composite. Thermochimica Acta, 619, 16-19, 2015.
71. Diez N., Díaz P., Álvarez P., González Z., Granda M., Blanco C., Santamaria R., Menéndez R., Activated carbon fibers prepared directly from stabilized fibers for use as electrodes in supercapacitors. Materials Letters, 136, 214-217, 2014.

72. Lee H.M., Kwac L.K., An K. H., Park S.J., Kim B.J., Electrochemical behavior of pitch-based activated carbon fibers for electrochemical capacitors. Energy Conversion and Management, 125, 347-352, 2016. 